\title{
Factors affecting Perceived Organizational Resilience: The case of Wine Tourism enterprises
}

\author{
Liontakis $\mathrm{A}^{1 *}$, Alebaki $\mathrm{M}^{2}$ and Koutsouris $\mathrm{A}^{3}$
}

${ }^{1}$ Post-Doctoral Fellow, Department of Agricultural Economics \& Rural Development, Agricultural University of Athens, Iera Odos 75, 11855, Athens ${ }^{2}$ Post-Doctoral Fellows, Department of Agricultural Economics \& Rural Development, Agricultural University of Athens, Iera Odos 75, 11855, Athens ${ }^{3}$ Professors, Department of Agricultural Economics \& Rural Development, Agricultural University of Athens, Iera Odos 75, 11855, Athens

DOI: $10.36347 /$ sjebm.2020.v07i01.002

| Received: 21.12.2019 | Accepted: 09.01.2020 | Published: 16.01.2020

*Corresponding author: Liontakis Angelos

\section{Abstract} Original Research Article

Resilience has emerged as a transdisciplinary concept in scientific research, being applied in a wide range of scientific disciplines. This study explores Organizational Resilience of the tourism hosting wineries. More specifically, it estimates Organizational Resilience scores of tourism hosting wineries using a composite index approach. Utilizing recent literature in the field, perceived Organizational Resilience is composed of perceived Planned and Adaptive Resilience, each of which is estimated using a group of Likert-scale statements. Using Crete as a case study, this study investigates the association of spatial characteristics of wineries, wine tourism entrepreneur's profile as well as profile and management of wine tourism enterprises with the Organizational Resilience and its components. On average, the perceived Organizational Resilience and its components can be considered relatively high. Adaptive Resilience seems to be more important for Cretan tourism hosting wineries indicating that winemakers consider more important to adjust after crises rather than be ready to confront crises. In addition, nonparametric statistics reveal various factors that affect perceived Organizational Resilience and its components. Male entrepreneurs assign higher Adaptive Resilience scores than female, while geographical location seems to significantly affect resilience scores. Level of innovation and the size of the enterprise tend to positively affect resilience scores. On the contrary, family contribution in terms of labour negatively affects resilient scores, which could link to possible lack of expertise among family members regarding wine tourism activity. Finally, managerial practices like keeping records about visitors and wine bottle price segmentation also affect Planned and/or Adaptive Resilience scores.

Keywords: wine tourism; Organizational Resilience.

Copyright @ 2020: This is an open-access article distributed under the terms of the Creative Commons Attribution license which permits unrestricted use, distribution, and reproduction in any medium for non-commercial use (NonCommercial, or CC-BY-NC) provided the original author and source are credited.

\section{INTRODUCTION}

Over the last decades, resilience has emerged as a transdisciplinary concept in scientific research, being applied in a wide range of disciplines, including ecology (see [1] for a review), regional studies (see [2] for a review); psychology (see [3] for a review); and supply chain management (see [4] for a review) to name but a few. Resilience has been associated with the capacity of an element to return to a stable state after a disruption [5]. It can be defined as the ability of a system to experience shocks while retaining a certain qualitative condition, structure and functions [6].

When the notion of resilience is applied to organizations (or enterprises), the above definition does not drastically change. It refers to the ability of an organization to anticipate, prepare for, respond and adapt to changes and sudden disruptions [7].
Organizational Resilience integrates two core components, namely, Planned and Adaptive Resilience [8]. Planned Resilience occurs prior to a crisis (predisaster), whereas Adaptive Resilience typically emerges after the crisis (post-disaster). Typically, Adaptive Resilience requires specific skills and attributes like leadership and ability to learn from past experiences as well as networking, internal collaboration and staff well-being [9]. In the tourism sector, Prayag et al. [10] investigate the relationship between Planned and Adaptive Resilience and financial performance of tourism firms, highlighting the complexities amongst these constructs.

A common concern regarding resilience is that it can only be demonstrated in the face of adversity and therefore the a priori examination of resilience is a rather difficult task [11]. Resilience metrics usually assessing actual resilience by approaching "perceived resilience". In this sense, survey respondents 
subjectively rate their level of agreement with specific statements expressing resilience properties [11].

While a stream of literature has focused on Organizational Resilience (see [12] and [13] for a review), including tourism research (e.g. [14] and [15]), no published work has explored the Organizational Resilience of wine tourism firms. To our knowledge, Alebaki \& Ioannides [16], who examined the challenges that surround the development of Greece's wine tourism constitutes the only exception.

To fill this gap, this study aims to explore the factors that affect the perceived Organizational Resilience of wine tourism enterprises. Using Crete as a case study, this paper employed a census survey to investigate the association between spatial characteristics of wineries, winemakers' profile and perceived Organizational Resilience. The following section presents the methodology employed in this research. Results are presented in the subsequent section. Finally, the conclusions section summarizes the results and underline future research needs.

\section{RESEARCH METHODOLOGY}

"Wines of Crete" was founded in 2006; today, it constitutes one of the fastest growing and best organized wine producers' associations, including 33 wineries-members [17]. Primary data used in this study were collected under a fieldwork involved on-site visits and personal interviews with 32 out of 33 winery operators of the 'Wines of Crete', using a census questionnaire, yielding a response rate of $97.0 \%$. It should be emphasized that respondents represent an important percentage of Cretan wineries. Overall, tourism hosting wineries account for $43 \%$ of the total number of Cretan wineries (32 out of 75 wine enterprises)

To estimate perceived Organizational Resilience, the questionnaire included a section with 11 Likert-type questions, using an adjusted version of Prayag et al. [10] composite scales (see Table 1). The latter were modified by combining various single-statement scales into one item [18]. Each single-scale captures a component of the concept, and together they produce one measure of a more complex issue [19]. In our analysis, Adaptive Resilience and Planned Resilience scores are estimated using six and five statements, respectively. Then, the Organizational Resilient score for each tourism hosting winery is estimated as:

$$
O R=\frac{\frac{\sum_{i=1}^{a} A S_{i}}{a}+\frac{\sum_{i=1}^{p} P S_{i}}{p}}{2}
$$

Where

OR: Organizational Resilience

$\mathrm{AS}_{\mathrm{i}}$ : Statement used to estimate Adaptive Resilience $\mathrm{PS}_{\mathrm{i}}$ : Statement used to estimate Planned Resilience a: number of statements used to estimate Adaptive Resilience

$\mathrm{p}$ : number of statements used to estimate Planned Resilience

After the estimation of the perceived Organizational Resilience score (including the Adaptive and Planned components), a second-stage analysis is implemented to understand the structure of Organizational Resilience and to explore its association with spatial patterns, wine tourism entrepreneurs' profiles as well as profile and management of wine tourism enterprises.

\section{Table-1: Statements used to estimate Organizational Resilience and its components i.e. Adaptive and Perceived} Resilience

\begin{tabular}{|c|}
\hline Adaptive Resilience \\
\hline A1. We develop relationships with other businesses that we may need to work with in the event of a crisis. \\
\hline A2. The enterprise's available resources are sufficient enough to deal effectively with unexpected changes. \\
\hline $\begin{array}{l}\text { A3. The leadership skills of those who run the business are sufficient enough to deal with a potential crisis } \\
\text { on our own. }\end{array}$ \\
\hline A4. Our staff is dedicated to take care of any issue until it is resolved. \\
\hline A5. If any member of our staff is absent, we have the ability to temporary assign his/her responsibilities \\
\hline A6. We have the ability to take immediate decisions. \\
\hline Planned Resilience \\
\hline P1. We stay updated with the latest trends in the industry so that we are prepared for possible disturbances. \\
\hline P2. We have clearly set out the priorities of the strategy we follow in the event of a crisis. \\
\hline P3. We place particular emphasis on developing the capacity to deal with unexpected conditions. \\
\hline P4. Given our emphasis on planning, we are well prepared for the 'unexpected'. \\
\hline P5. In order to be effective, emergency plans should be pilot tested. \\
\hline
\end{tabular}

The second stage analysis is applied by utilizing nonparametric statistical tools. Their main advantages is that they have less stringent assumptions than the traditional parametric counterparts, especially in cases where distributional assumptions are violated, limited data is available and observations are nominal or ordinal and subject to outliers [20]. In particular, the 
following nonparametric tests are performed (see also Table 2):

- Mann-Whitney test is applied to compare Organizational Resilience and its components between two groups, as defined by binary variables (e.g. gender);
- Kruskal Wallis test is utilized to compare Organizational Resilience and its components among more than two groups (e.g. age class); and

- Spearman correlation coefficient is applied which allows to explore the correlation between Adaptive and Perceived Resilience as well as the relationship of Organizational Resilience and its components with continuous variables (e.g. vineyards cultivated area)

Table-2: Nonparametric tests and their usage to assess the effect of various variables on perceived Organizational (adaptive and planned) resilience.

\begin{tabular}{|l|l|l|l|}
\hline $\begin{array}{l}\text { Nonparametric } \\
\text { test }\end{array}$ & Spatial structures & $\begin{array}{l}\text { Wine tourism } \\
\text { entrepreneur's } \\
\text { profile }\end{array}$ & Profile and management of wine tourism enterprises \\
\hline Mann-Whitney & $\begin{array}{l}\text { 1. Prefecture } \\
\text { (Heraklion vs. } \\
\text { Chania) }\end{array}$ & 1. Gender & 1. Keeping records on visitation numbers, etc \\
\hline Kruskal-Wallis & & & $\begin{array}{l}\text { 1. Proximity to the } \\
\text { airport } \\
\text { Spearman }\end{array}$ \\
$\begin{array}{l}\text { 2. Proximity to } \\
\text { 3. Number of } \\
\text { nearby wineries } \\
\text { (<10km) }\end{array}$ & $\begin{array}{l}\text { 1. Winery age } \\
\text { 2. Share of family owned to total vineyards area } \\
\text { 3. Share of family labour to total labour } \\
\text { 4. Cultivated land (vineyards) } \\
\text { 5. Share of own-produced cellar door sales to total sales } \\
\text { 6. Number of full-time permanent employees } \\
\text { 7. Share of own-produced raw material }\end{array}$ \\
\hline
\end{tabular}

\section{RESULTS \\ Spatial structures}

With respect to their spatial distribution, the majority of Wines of Crete members $(69 \%)$ is concentrated in the Prefecture of Heraklion. The rest are located in Chania (19\%), Rethymno (9\%) and Lasithi (3\%) Prefectures (see Figure 1).

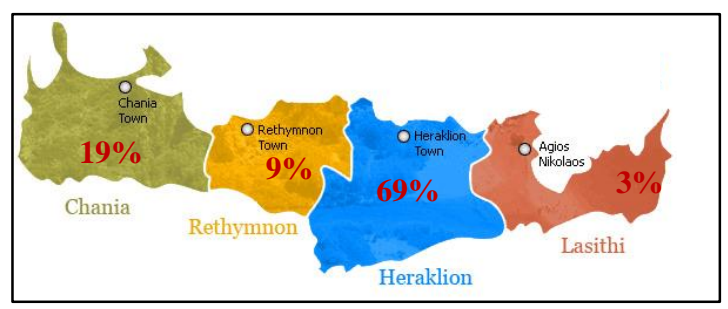

Fig-1: Spatial distribution of Cretan Wineries Map retrieved by: http://www.greekislands.us/crete/crete-information/

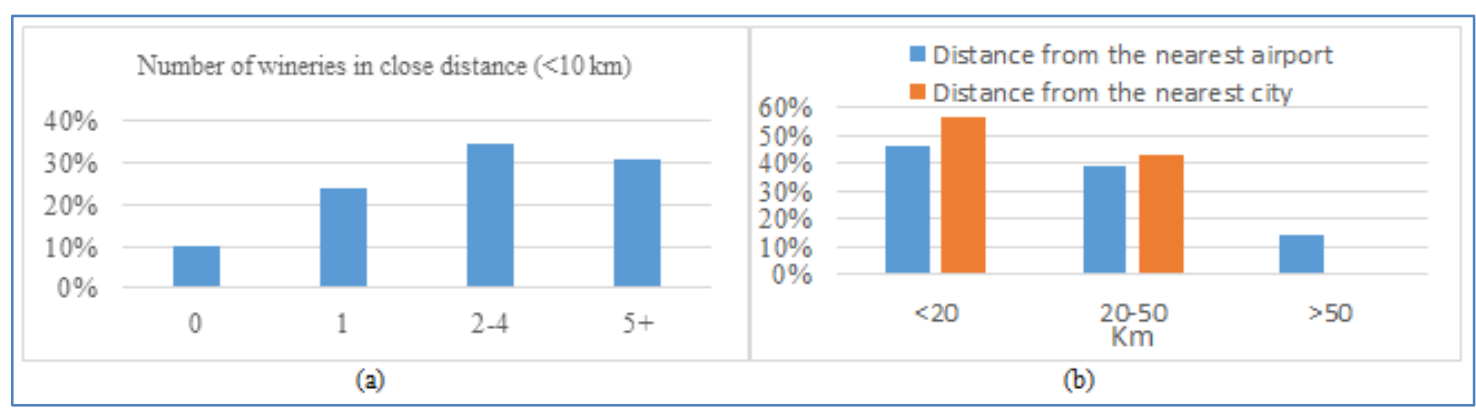

Fig-2: Number of wineries in distance less than $10 \mathrm{~km}(\mathrm{a})$; Proximity to airport and urban areas (b)

In terms of location, wineries are relatively dispersed around Prefectures and are not always in close proximity to urban centres or airports. More specifically, $46 \%$ and $57 \%$ of them are located at a distance of less than $20 \mathrm{~km}$ from urban centre and airport, respectively. Moreover, the so-called critical mass of wineries has been found in specific wine regions, i.e., Archanes in Heraklion district (right bar in Figure 2).

\section{Wine tourism entrepreneur's profile}

Apparently, the wine tourism sector in Crete is being dominated by males (70\%). In terms of age, more than $50 \%$ of the winemakers belong to the $40-64$ categories. However, there is also an important number of winemakers who are young $(32 \%)$, reflecting the increased potential of the sector (Figures $3 a-b)$. 


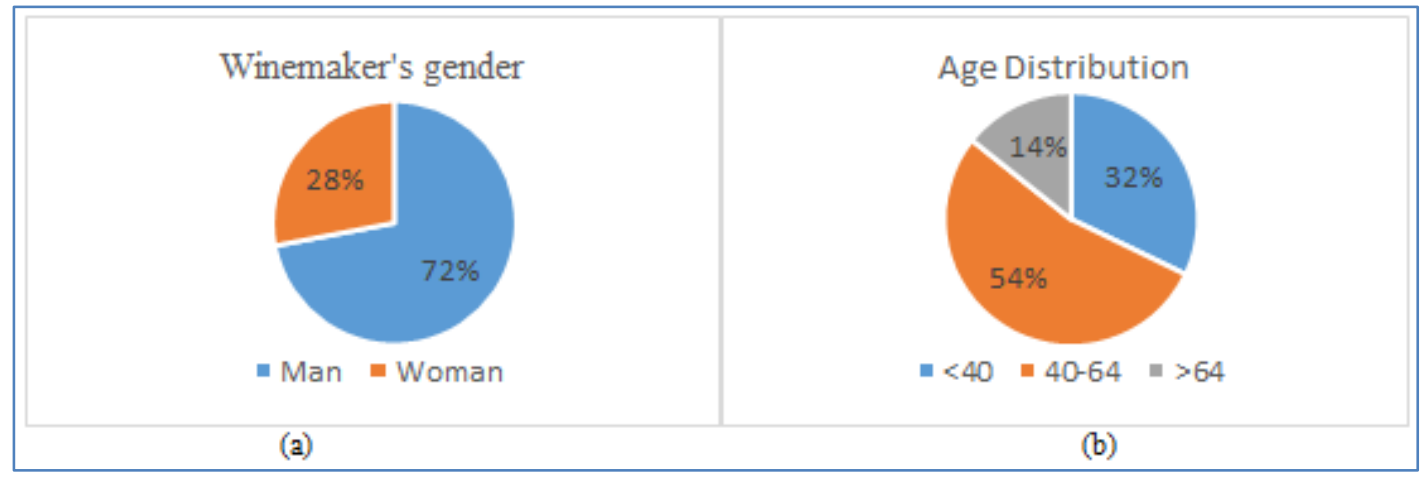

Fig-3: Gender (a) and age (b) distribution

Profile and management of wine tourism enterprises

The vast majority of the wineries are family enterprises (94\%). Figures $4 \mathrm{a}-4 \mathrm{~b}$ presents some characteristics regarding the size of the wineries (distribution of the number of permanent employees and of the vineyard cultivated area).

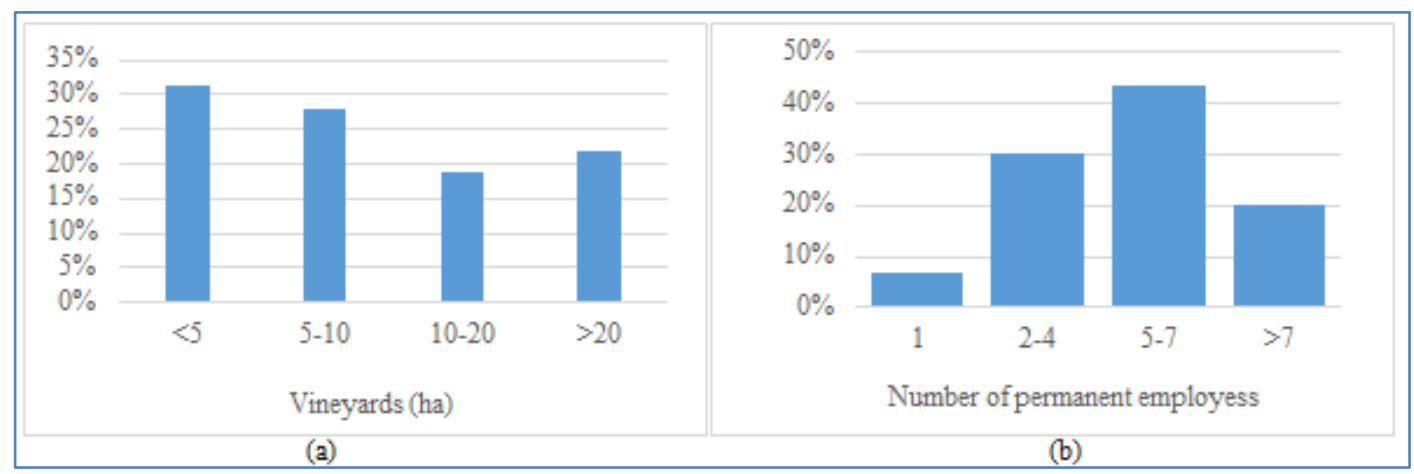

Fig-4: Distribution of wineries vineyard's area (a); number of permanent employees (b)

It is also important to emphasize that, on average, the $80 \%$ of the agricultural land is owned to the winery, while about $60 \%$ of the wineries rent less than $5 \%$ of the total cultivated land (vineyards) (Figure 5a). This is an indication of how winemakers value ownership and self-sufficiency, characteristics that considered crucial for enterprise resilience. The distribution of the share of family to total labour does not hold the same pattern. While many wineries (about $30 \%$ ) have high share of family labour, an equal part of wineries has less than $25 \%$ share of family labour (Figure 5b). On average, the share of family to total labour is equal to $54 \%$.

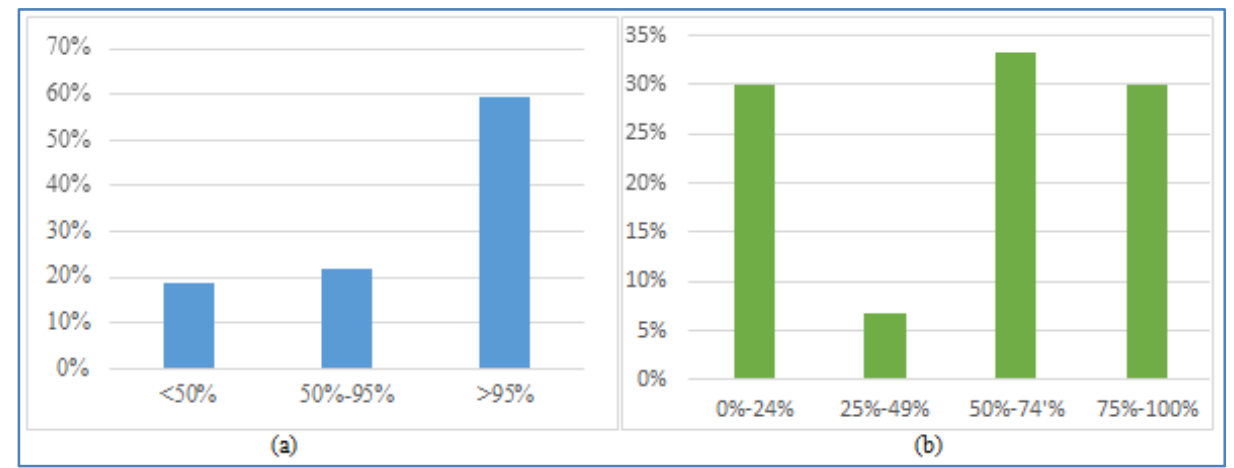

Fig-5: Share of family-owned to total cultivated vineyards (a); Share of family labour to total labour (b)

Unsurprisingly, income diversification from wine tourism is still limited in most of the Cretan tourism hosting wineries. In the $55 \%$ cases, the share of cellar door sales to the total revenues is lower than $10 \%$. There are, however, cases of high cellar door sales (more than 30\%) (Figure 6a). Figure $6 \mathrm{~b}$ presents the different visiting patterns that Cretan tourism hosting wineries apply. In about half cases (47\%) tourists can visit the wineries in a specific timetable throughout the year. In the rest cases, tourists can visit wineries only after appointment or in a specific timetable but only in a certain period of the year. 


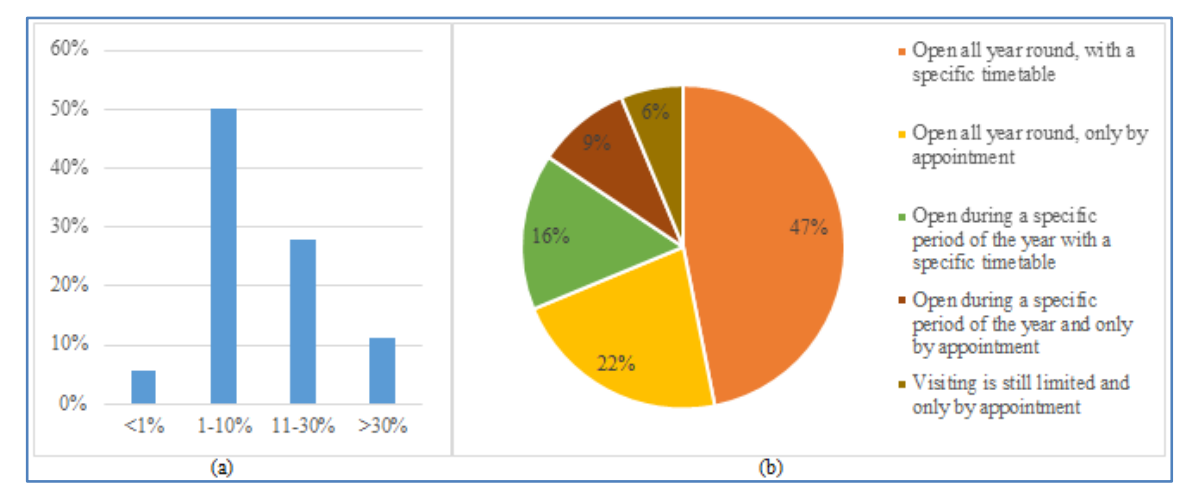

Fig-6: Share of cellar door sales to total sales (a) and visiting patterns of tourism hosting wineries (b).

As far as the wine bottle price segmentation is concerned, we consider Terziyska [21] segmentation who classified three distinct groups of price range, namely: basic class (less than or equal to $5 € /$ bottle); medium class (more than $5 € /$ bottle and less than $10 € /$ bottle) and high-class wine (more than $10 € /$ bottle). Applying this classification, the $38 \%$ of the Cretan tourism hosting wineries offer all wine classes. The majority of the wineries offers medium and high-class wine class, while only one winery exclusively offers high class wine. The above situation clearly indicates that most of the wine tourism entrepreneurs/managers have not yet clearly set a segmentation strategy and therefore, they still don't target to a specific customers' profile.

Finally, adoption of innovation has been reported using a Likert-scale class based on wineries' reputation for using innovation. The distribution of innovation classes is presented in Figure 7. On average, Cretan tourism hosting wineries have a score of 3.6, indicating a relatively high score on innovation adoption, even though few wineries have score equal to five.

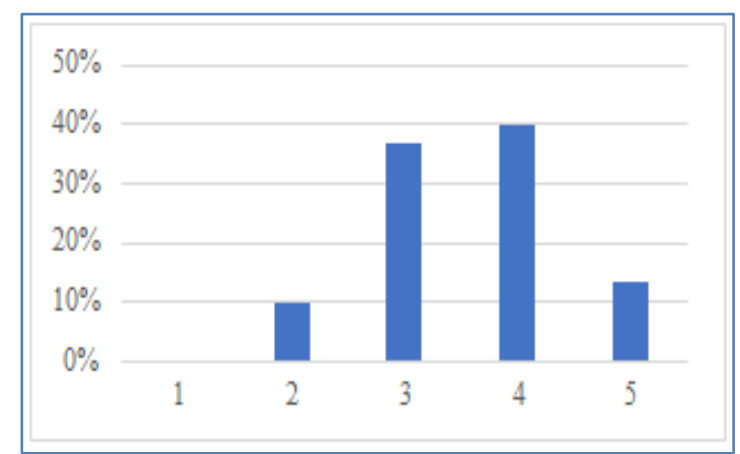

Fig-7: Distribution of wine tourism enterprises' innovation classes

\section{Perceived Organizational Resilience, Adaptive Resilience and Planned Resilience}

Figure 8 provide the average score of the fivepoint Likert-scale statements used to estimate perceived Organizational Resilience and Table 4 presents descriptive statistics for the Organizational Resilience and its components (Planned and Adaptive Resilience). Cronbach's a for Adaptive and Planned Resilience indicators are 0.65 and 0.72 which can be considered as satisfactory [22]. Items A1-A6 corresponds to Adaptive Resilience statements, while items P1-P5 correspond to Planned Resilience statements.

In general, the average scores of each statement is higher than 3, indicating that the wine tourism entrepreneurs assign a relatively high level of Organization Resilience for their wine tourism activity. In several cases, though, the standard deviation is high, indicating a high variation of the responses. Interestingly, the three out of four scores above " 4 " correspond to Adaptive Resilience. Moreover, Adaptive Resilience statements have the lowest variation among entrepreneurs providing an indication that, in general, wine tourism entrepreneurs agreed that Adaptive Resilience is more important and better fit to their personality. Another fact in favour of the above indication is the higher average scores that Adaptive Resilience statements get (3.8) against Planned Resilience (3.5).

Table 3 presents the descriptive statistics for Planned, Adaptive and Organizational Resilience while Figure 9 presents the dispersion of Planned and Adaptive Resilience across the tourism hosting wineries. Obviously, the vast majority of the wineries are presented in up-right part of the chart, indicating high perceived Planned and Adaptive Resilience. This corresponds with the high correlation among Planned and Adaptive Resilience (0.48). On the other hand, there are few wineries (five) located in the up-left part of the graph indicating high adaptive but low Planned Resilience. Moreover, only one winery consider itself as a low-resilient tourism hosting winery, both in terms of Adaptive and Planned Resilience. Finally, nobody assigns low Adaptive but high Planned Resilience score to his/her win tourism enterprise. 


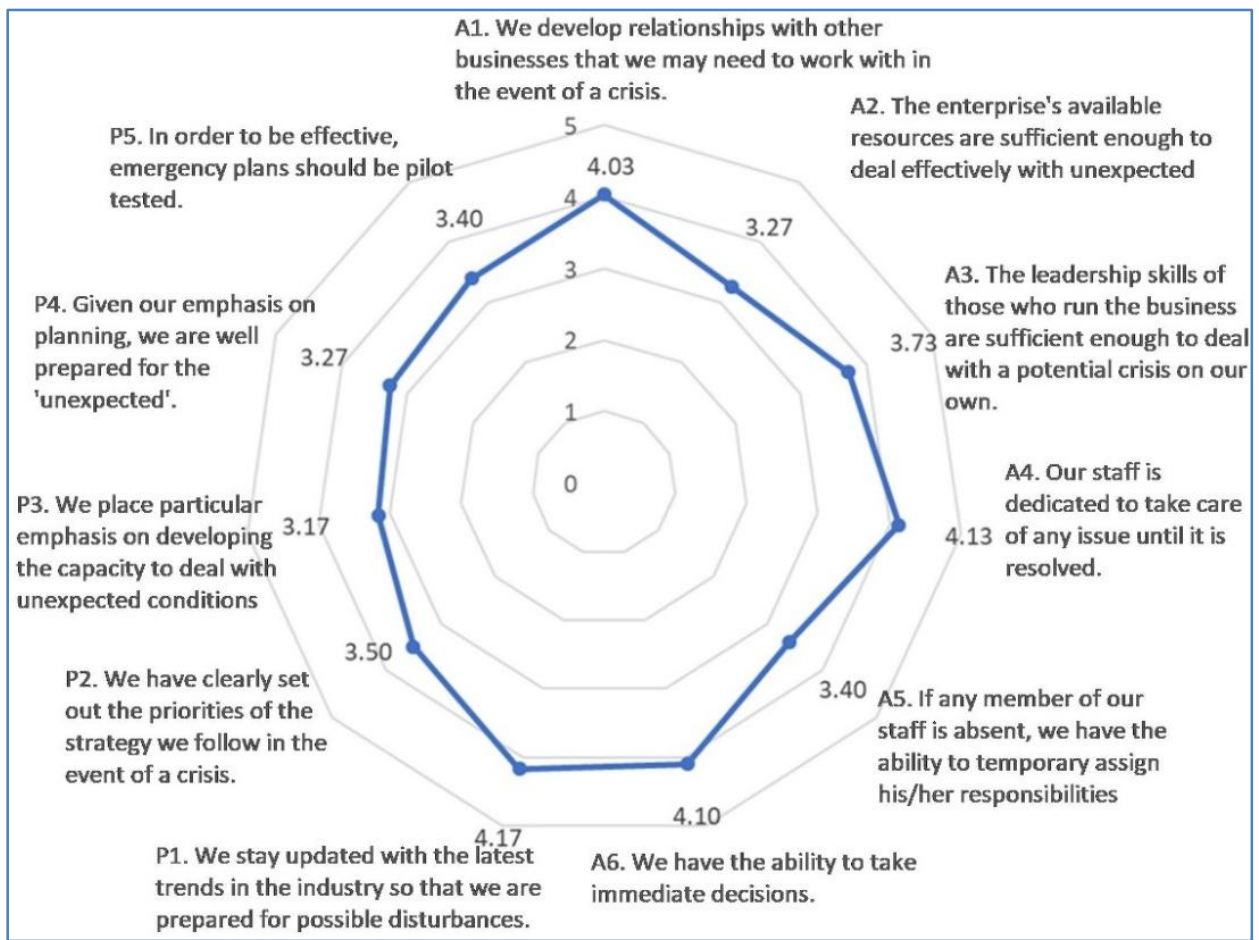

Fig-8: Average score of the items used to estimate Perceived Resilience. Items A1-A6 corresponds to Adaptive Resilience statements, while items P1-P5 correspond to Planned Resilience statements

Table-3: Descriptive statistics of Organizational Resilience and its Components (Planned and Adaptive Resilience)

\begin{tabular}{|l|l|l|l|l|}
\hline & Average & Min & Max & St. Deviation \\
\hline Planned Resilience & 3.5 & 1.80 & 4.60 & 3.60 \\
\hline Adaptive Resilience & 3.8 & 2.17 & 4.83 & 3.50 \\
\hline Organizational Resilience & 3.6 & 2.38 & 4.62 & 3.55 \\
\hline
\end{tabular}

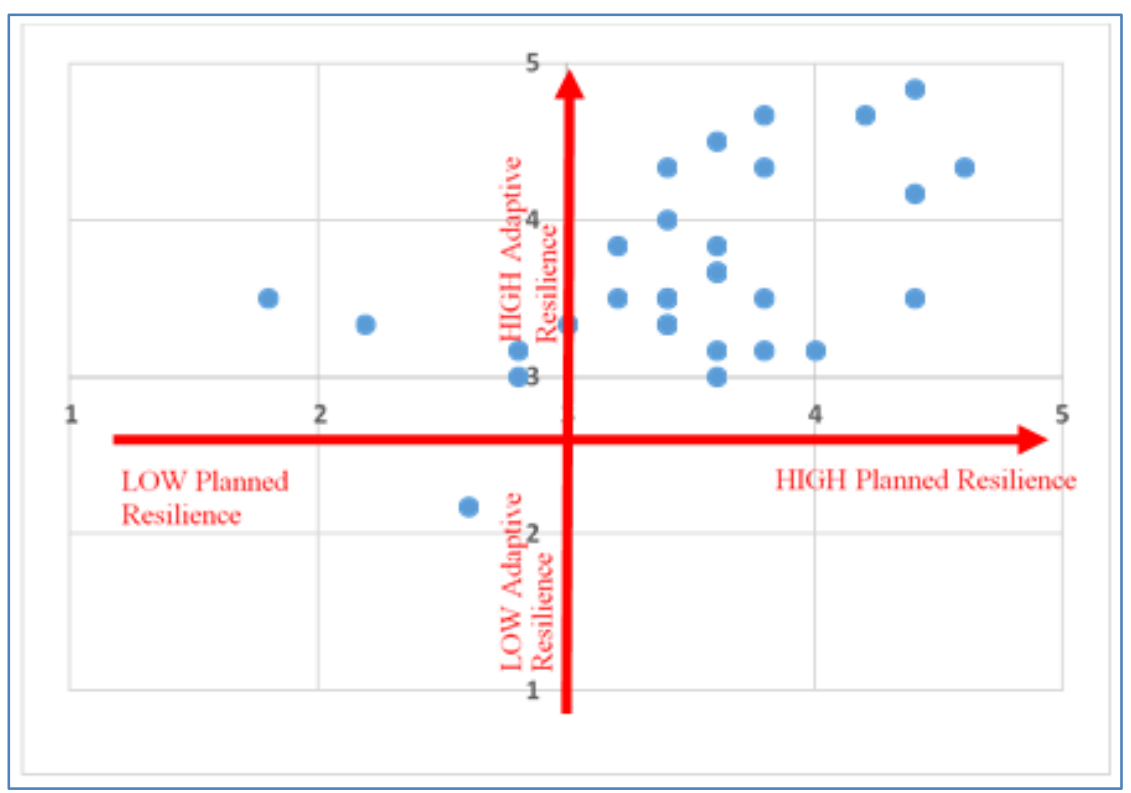

Fig-9: Dispersion of Planned and Adaptive Resilience

Factors affecting Perceived Organizational Resilience, and its components (Adaptive and Planned Resilience) Tables 4-6 presents the main outcomes of the nonparametric tests that used to assess the effect of various factors on Perceived Organizational Resilience, and its components (Adaptive and Planned Resilience).

\section{Spatial structures}

Location of the wineries proved to be an important element but only for the determination of Planned Resilience and only in terms of the Prefecture where the tourism hosting winery is located. More specifically, the wineries which are located in Chania Prefecture tends to have statistically significant higher 
Planned Resilience compared to those located in Heraklion Prefecture (the other two Cretan Prefectures have been excluded from the analysis due to their low share in the sample). This is an interesting finding that need more examination to identify the exact reasons behind it. A possible explanation could be that amongst the six wineries of the sample that have been established in Chania Prefecture, there are some successful cases that present high potential for further development. On the contrary, in the case of the wineries located in Heraklion Prefecture, the successful cases cannot easily affect the Prefecture average due to the higher total number of wineries. In any case, this difference in Planned Resilience score is not enough to significantly affect the Organizational Resilience between these two groups. In addition, the wine tourism entrepreneurs do not consider important the presence of geographical clusters of wine tourism enterprises in the Heraklion Prefecture as the correlations of Resilience with proximity indices are very weak (see Table 4). Likewise, proximity to the airport and urban centres do not consider important (see Table 4).

\section{Wine business entrepreneur's profile}

Interestingly, gender of the owner significantly affects the Adaptive component of Organizational Resilience. Mann-Witney test (see Table 4) indicates that male entrepreneurs considered themselves more capable of adapting in emergency cases, and thus have a statistically significant higher Adaptive Resilience score compared with female (3.82). However, this difference is not sufficient enough to significantly affect the Organizational Resilience scores between male and female entrepreneurs.

As far as the age of the wine tourism entrepreneur is concerned, it has a negative but not statistically significant effect on the resilience scores, which is an indication that younger entrepreneurs consider their enterprise less resilient that the -more confident- older entrepreneurs.

\section{Profile and management of wine tourism enterprises}

Many factors of this group are related to family ownership and independency. Table 6 presents the correlation of perceived Organizational Resilience and its components with the variables: Share of family labour to total labour; Share of family-owned land to total cultivated land and Share of owned-produced raw material. In the most cases, a negative but not statistically significant correlation exists among the aforementioned variables and perceived Organizational Resilience and its components. The only statistically significant correlation exists between Planned Resilience and share of family labour to total labour. This negative relationship may exist because in many cases, high shares co-exist with lower technical knowhow and expertise in wine tourism activity which in turn affects the Organizational Resilience of the winery.

Two variables in this category reflect the size of the enterprise. More specifically, the correlation of Organizational Resilience and its components with the number of full-time permanent employees and the size of the cultivated area (vineyards) is examined. The latter variable has positive and statistically significant correlation with Organizational Resilience as well as with Adaptive and Planned Resilience. This is an indication that the wineries which utilize large cultivated areas have better-establish enterprises and more confidence for their survival and prosperity after external shocks.

The final set of issues that are examined in this category regards the management of the wineries. Mann-Whitney tests (Table 5) reveals that tourism hosting wineries which are open throughout the year at a specific timetable have higher Adaptive Resilience that the others. Adaptive Resilience is also significantly higher in wine tourism enterprises that have no clear price segmentation strategy. The final issue that MannWitney test reveals that keeping statistics on the visitors is a factor that drastically increases Planned Resilience.

In addition, Kruskal-Wallis test has been used to compare Organizational Resilience and its components among the groups of innovation defined by a Likert-scale statement. Results indicate that the level of innovation has a strong positive effect on the Organizational Resilience score as well as in the score of Adaptive and Planned Resilience (see Table 6). Therefore, innovative wine tourism entrepreneurs tend to assign higher scores of Organizational Resilience to their enterprise. 
Table-4: Results of the Mann-Whitney tests

\begin{tabular}{|c|c|c|c|c|c|}
\hline & Average & St.dev & Average & St.dev. & $\begin{array}{c}\text { Mann- } \\
\text { Whitney }\end{array}$ \\
\hline $1^{\text {st }}$ test: Spatial distribution & \multicolumn{2}{|c|}{ Heraklion } & \multicolumn{2}{|c|}{ Chania } & \\
\hline Adaptive Resilience & 3.65 & 0.60 & 3.92 & 0.64 & $z=-0.689$ \\
\hline Planned Resilience & 3.36 & 0.58 & 3.93 & 0.60 & $\mathrm{z}=-1.881 *$ \\
\hline Organizational Resilience & 3.51 & 0.51 & 3.93 & 0.53 & $\mathrm{z}=-1.400$ \\
\hline $2^{\text {nd }}$ test: Gender & \multicolumn{2}{|c|}{ Male } & \multicolumn{2}{|c|}{ Female } & \\
\hline Adaptive Resilience & 3.82 & 0.56 & 3.32 & 0.55 & $\mathrm{z}=-1.960 * *$ \\
\hline Planned Resilience & 3.48 & 0.70 & 3.53 & 0.58 & $\mathrm{z}=0.457$ \\
\hline Organizational Resilience & 3.65 & 0.55 & 3.42 & 0.51 & $\mathrm{z}=-0.838$ \\
\hline $3^{\text {rd }}$ test: Business hours & \multicolumn{2}{|c|}{$\begin{array}{l}\text { Open all year round, with a specific } \\
\text { timetable }\end{array}$} & \multicolumn{2}{|c|}{ Other } & \\
\hline Adaptive Resilience & 3.78 & 0.61 & 3.56 & 0.55 & $\mathrm{z}=-1.713^{*}$ \\
\hline Planned Resilience & 3.56 & 0.52 & 3.43 & 0.58 & $\mathrm{z}=0.147$ \\
\hline Organizational Resilience & 3.67 & 0.54 & 3.49 & 0.51 & $\mathrm{z}=-0.975$ \\
\hline $4^{\text {th }}$ test: Price segmentation & \multicolumn{2}{|c|}{ All wine price classes } & \multicolumn{2}{|c|}{ Other } & \\
\hline Adaptive Resilience & 3.86 & 0.44 & 3.56 & 0.65 & $\mathrm{z}=-1.741 *$ \\
\hline Planned Resilience & 3.58 & 0.23 & 3.35 & 0.70 & $z=-0.912$ \\
\hline Organizational Resilience & 3.71 & 0.30 & 3.45 & 0.58 & $\mathrm{z}=-1.355$ \\
\hline $\begin{array}{l}5^{\text {th }} \text { test: Keeping statistics on } \\
\text { visitors }\end{array}$ & \multicolumn{2}{|c|}{ Yes } & \multicolumn{2}{|c|}{ No } & \\
\hline Adaptive Resilience & 3.70 & 0.57 & 3.63 & 0.67 & $\mathrm{z}=0.084$ \\
\hline Planned Resilience & 3.75 & 0.52 & 3.15 & 0.63 & $\mathrm{z}=-2.345 * *$ \\
\hline Organizational Resilience & 3.72 & 0.49 & 3.39 & 0.56 & $\mathrm{z}=-1.214$ \\
\hline
\end{tabular}

* statistical significance at 0.1 level

** statistical significance at 0.05 level

Table-5: Results of the Kruskal-Wallis test

\begin{tabular}{|l|c|c|c|c|c|c|c|c|l|}
\hline $\begin{array}{l}\text { Innovation level } \\
\text { (Likert-scale) }\end{array}$ & \multicolumn{2}{|c|}{$\mathbf{2}$} & \multicolumn{2}{c|}{$\mathbf{3}$} & \multicolumn{2}{c|}{$\mathbf{4}$} & \multicolumn{2}{c|}{ 5 } & $\begin{array}{l}\text { Kruskal- } \\
\text { Wallis }\end{array}$ \\
\cline { 2 - 10 } & Average & St.dev & Average & $\begin{array}{c}\text { St. } \\
\text { dev. }\end{array}$ & Average & St.dev. & Average & St.dev. & W. \\
\hline $\begin{array}{l}\text { Adaptive } \\
\text { Resilience }\end{array}$ & 3.00 & 0.72 & 3.64 & 0.52 & 3.71 & 0.60 & 4.13 & 0.44 & $\chi^{2}=4.571$ \\
\hline Planned Resilience & 2.87 & 0.83 & 3.20 & 0.59 & 3.67 & 0.37 & 4.25 & 0.44 & $\chi^{2}=10.069^{* *}$ \\
\hline $\begin{array}{l}\text { Organizational } \\
\text { Resilience }\end{array}$ & 2.93 & 0.65 & 3.42 & 0.49 & 3.69 & 0.42 & 4.19 & 0.23 & $\chi^{2}=9.028^{* *}$ \\
\hline
\end{tabular}

* statistical significance at 0.1 level

** statistical significance at 0.05 level

Table-6: Spearman correlation coefficient among Organizational Resilience (and its components) with various factors

\begin{tabular}{|l|c|c|c|}
\hline & $\begin{array}{c}\text { Adaptive } \\
\text { Resilience }\end{array}$ & $\begin{array}{c}\text { Planned } \\
\text { Resilience }\end{array}$ & $\begin{array}{c}\text { Organizational } \\
\text { Resilience }\end{array}$ \\
\hline Number of nearby wineries (<10km) & 0.0665 & 0.1539 & 0.106 \\
\hline Number of permanent employees & 0.0655 & 0.0417 & 0.0397 \\
\hline Owner age & -0.2292 & -0.2507 & -0.2902 \\
\hline Proximity to airport & -0.0819 & -0.1425 & -0.0778 \\
\hline Proximity to cities & 0.1227 & 0.0289 & 0.1229 \\
\hline Share of cellar-door sales to total revenues & -0.1527 & -0.154 & -0.148 \\
\hline Share of family to total labour & -0.0481 & $-0.3853^{*}$ & -0.2391 \\
\hline Share of family-owned land to total land & -0.1138 & 0.2619 & -0.1802 \\
\hline Share of owned-produced raw material & -0.1527 & 0.154 & -0.148 \\
\hline Utilized land (vineyards) & $0.5222^{*}$ & $0.5659^{*}$ & $0.5866^{*}$ \\
\hline
\end{tabular}

* Statistical significance at 0.1 level 


\section{CONCLUSION}

The concept of perceived Organizational Resilience of wine tourism enterprises has been explored utilizing primary data collected from Cretan tourism hosting wineries. Organizational Resilience has been estimated using two groups of Likert-scale statements, each of which approaches the two different components of Organizational Resilience, namely Planned and Adaptive Resilience [10]. On average, the perceived Organizational Resilience can be considered relatively high as well as its two components. Adaptive Resilience seems to be more important than Planned Resilience for Cretan tourism hosting wineries. This fact may reflect the belief of winemakers that it is more important to have the necessary skills to adjust after crises rather than be prepared to confront crises.

At the second stage of the analysis, nonparametric statistics reveal various factors that affect perceived Organizational Resilience and its components. Factors like the gender of the wine tourism entrepreneur and location structure seem to significantly affect resilience scores. Level of innovation and the size of the enterprise tend to positively affect resilience scores while, on the contrary, family contribution negatively affect resilient scores. Finally, several managerial practices like keeping records about visitors and wine bottle price segmentation affect Planned and/or Adaptive Resilience.

As this study is part of a broader research project, further exploration needs to be done to finetuning the actual level of impact of the examined various factors upon Organizational Resilience as well as to better understand the exact way that these factors act. Future studies can also add to this research field by combining performance indicators with perceived resilience metrics to approach more robustly and precisely the actual Organization Resilience.

\section{ACKNOWLEDGEMENTS}

This Research Project was funded by the Program encoded EDBM34, titled "Support of researchers with emphasis on young researchers". It was co-financed by the Operational Program and by the European Union (European Social Fund) and National Strategic Reference Framework of Greece, under the priority axis "Development of Human Resources, Education and Lifelong Learning (ESPA 2014-2020)”.

\begin{tabular}{|ll|}
\hline$* * *$ & $\begin{array}{c}\text { Operational Programme } \\
\text { Human Resources Development, } \\
\text { Education and Lifelong Learning } \\
*_{*}^{*} *^{*}\end{array}$ \\
\hline $\begin{array}{c}\text { Eupwraïkn Evwon } \\
\text { Europesn Social Fund }\end{array}$ & co-financed by Greece and the European Union
\end{tabular}

\section{REFERENCES}

1. Quinlan AE, Berbés-Blázquez $\mathrm{M}$, Haider LJ, Peterson GD. Measuring and assessing resilience: broadening understanding through multiple disciplinary perspectives. Journal of Applied Ecology. 2016 Jun;53(3):677-87

2. Patel SS, Rogers MB, Amlôt R, Rubin GJ. What do we mean by'community resilience'? A systematic literature review of how it is defined in the literature. PLoS currents. 2017 Feb 1;9

3. Fletcher D, Sarkar M. Psychological resilience: A review and critique of definitions, concepts, and theory. European psychologist. 2013;18(1):12.

4. Kamalahmadi M, Parast MM. A review of the literature on the principles of enterprise and supply chain resilience: Major findings and directions for future research. International Journal of Production Economics. 2016 Jan 1; 171:116-33.

5. Bhamra R, Dani S, Burnard K. Resilience: the concept, a literature review and future directions. International Journal of Production Research. 2011 Sep 15;49(18):5375-93

6. Walker B, Holling CS, Carpenter S, Kinzig A. Resilience, adaptability and transformability in social-ecological systems. Ecology and society. 2004 Sep 16;9(2).

7. Denyer D. Organizational Resilience: A summary of academic evidence, business insights and new thinking. BSI and Cranfield School of Management, Cranfield. 2017 Jul 15.

8. Lee AV, Vargo J, Seville E. Developing a tool to measure and compare organizations' resilience. Natural hazards review. 2013 Jan 15;14(1):29-41.

9. Nilakant V, Walker B, van Heugen K, Baird R, De Vries H. Research note: Conceptualising Adaptive Resilience using grounded theory. New Zealand Journal of Employment Relations. 2014;39(1):79.

10. Prayag G, Chowdhury M, Spector S, Orchiston C. Organizational Resilience and financial performance. Annals of Tourism Research. 2018 Nov 1;73(C):193-6.

11. Tomyn AJ, Weinberg MK. Resilience and subjective wellbeing: A psychometric evaluation in young Australian adults. Australian Psychologist. 2018 Feb;53(1):68-76.

12. Annarelli A, Nonino F. Strategic and operational management of Organizational Resilience: Current state of research and future directions. Omega. 2016 Jul 1;62:1-8

13. Korber S, McNaughton RB. Resilience and entrepreneurship: a systematic literature review. International Journal of Entrepreneurial Behavior \& Research. 2018 Nov 9;24(7):1129-54

14. Prayag G, Chowdhury M, Spector S, Orchiston C. Organizational Resilience and financial 
performance. Annals of Tourism Research. 2018 Nov 1;73(C):193-6.

15. Orchiston C, Prayag G, Brown C. Organizational Resilience in the tourism sector. Annals of Tourism Research. 2016; 56:145-8.

16. Alebaki M, Ioannides D. Threats and obstacles to resilience: Insights from Greece's wine tourism. In Tourism, Resilience and Sustainability. 2017, (7): 132-148. Routledge.

17. Alebaki M, Koutsouris A. Wine Tourism Destinations Across the Life-Cycle: A Comparison of Northern Greece, Peloponnese and Crete. InWine Tourism Destination Management and Marketing. 2019: 463-482. Palgrave Macmillan, Cham.
18. Bernard HR. Research methods in anthropology: Qualitative and quantitative approaches. Rowman \& Littlefield; 2017 Nov 17.

19. Biggs D. Understanding resilience in a vulnerable industry: the case of reef tourism in Australia. Ecology and society. 2011 Mar 4;16(1).

20. Siegel S, Castellan NJ. Nonparametric statistics for the behavioral sciences. New York: McGraw-hill. 1956 Jun.

21. Terziyska I. Benchmarking wine tourism destinations-the case of Bulgaria. International Journal of Wine Business Research. 2017 Nov 20;29(4):384-400.

22. Taber KS. The use of Cronbach's alpha when developing and reporting research instruments in science education. Research in Science Education. 2018 Dec 1;48(6):1273-96. 